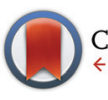

CrossMark \&lick for updates

Cite this: Org. Chem. Front., 2016, 3 1535

Received 25th July 2016

Accepted 23rd August 2016

DOI: $10.1039 / \mathrm{c} 6 q 000390 \mathrm{~g}$

rsc.li/frontiers-organic

\title{
New strategies and applications using electrophilic cyanide-transfer reagents under transition metal-free conditions
}

\author{
Johannes Schörgenhumer and Mario Waser*
}

The use of electrophilic cyanide-transfer reagents has become a versatile strategy to access important structural motives in a complementary way compared to other methods. Over the last few years a variety of different reagents have been very successfully employed for the cyanation of different nucleophiles. This article highlights some of the most recent impressive achievements in the field of transition metalfree electrophilic cyanation reactions, which have now become a powerful synthetic tool even with respect to asymmetric transformations.

\section{Introduction}

The use of cyanides for the construction of carbon-carbon bonds is one of the fundamental strategies in organic chemistry. ${ }^{1}$ The basic reactivity of simple cyanides (such as KCN)

Institute of Organic Chemistry, Johannes Kepler University Linz, Altenbergerstr. 69, 4040 Linz, Austria. E-mail: mario.waser@jku.at

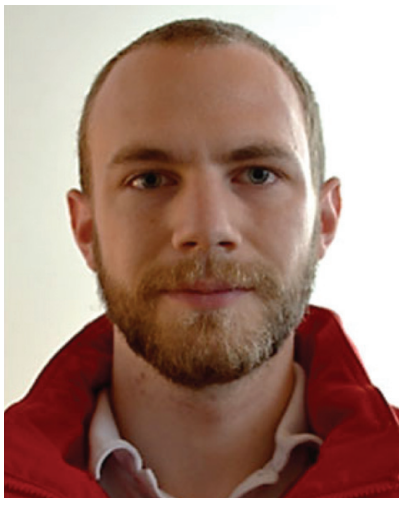

Johannes Schörgenhumer
Johannes Schörgenhumer was born in Wels, Austria, in 1990. He started studying chemistry at the Johannes Kepler University Linz in 2010, Austria, where he graduated in 2015 in Mario Waser's group. During his master thesis, he investigated novel reactions using iodine(III) reagents, such as the organocatalytic approach for asymmetric electrophilic cyanation reactions. Since November 2015, he continued his studies in the same group, currently working on his PhD with the main focus on asymmetric organocatalysis. that every undergraduate student learns in first year organic chemistry classes is that the inherent nucleophilicity of the cyanide ion $\mathrm{CN}^{-}$allows for powerful nucleophilic substitution or addition reactions, resulting in such important transformations like the Strecker amino acid synthesis or the Kolbe nitrile synthesis. ${ }^{1}$

On the other hand, inverting the reactivity of a cyanide reagent to obtain electrophilic formal $\mathrm{CN}^{+}$-transfer reagents

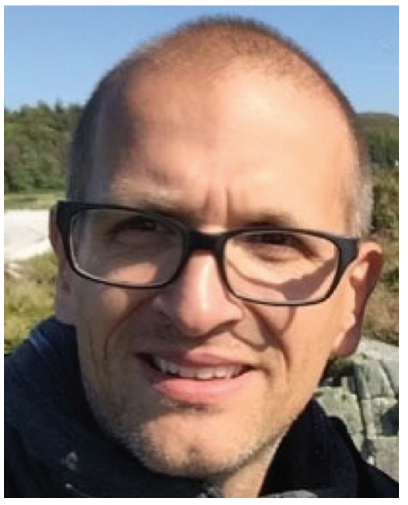

Mario Waser
Mario Waser was born in Steyr, Austria in 1977 and studied chemistry at the Johannes Kepler University Linz, Austria were he obtained his Ph.D. in 2005 in the group of Prof. Heinz Falk, working on the synthesis of hypericin-based photosensitizers. After a postdoctoral stay in the group of Prof. Alois Fürstner at the Max-Planck Institut für Kohlenforschung (Mülheim, Germany), where he was part of the team accomplishing the first total syntheses of iejimalide $B$ and iejimalide $A$, he spent two years as an R\&D chemist working for DSM Linz. In 2009 he started his independent career as an Assistant Professor at the JKU Linz. In 2014 he obtained his habilitation (venia docendi) and became Associate Professor. His main research interests are on the design and application of asymmetric organocatalysts like novel bifunctional phase-transfer catalysts, on ammonium enolatemediated reactions and on the use of hypervalente iodine-based reagents using asymmetric organocatalysis. 
requires special reagents and strategies to achieve cyanation of classical pronucleophiles like e.g. enolates. ${ }^{2-8}$ Compared to the standard use of nucleophilic CN-reagents, this reactivity Umpolung provides a complementary synthesis strategy, giving access to structural motives that are only difficult to access with other methods. ${ }^{2-8}$ Over the years a variety of different electrophilic cyanation reagents have been developed. The most classical and simple cases are cyanogen bromide ${ }^{6}$ and chloride $^{3}$ or dicyan. However, these compounds are highly toxic and also turned out to be of only limited applicability for more demanding (maybe even asymmetric) transformations. Thus, the development of better to handle and synthetically more versatile electrophilic CN-transfer reagents has been an important task. Seminal reports in their preparation date back to 1949 when Kurzer first described the synthesis of $\mathrm{N}$-cyano sulfonamides $^{2}$ and an early report describing the use of tosylcyanide $\mathbf{1}$ for electrophilic cyanation reactions was reported in 1981 already. ${ }^{4}$ A variety of different reagents have been reported since and the designer reagents 1-7 depicted in Scheme 1 have found the most widespread use for a variety of demanding and in some cases even asymmetric target reactions so far. ${ }^{9}$

These reagents have been successfully reacted with a large variety of different nucleophilic reagents (e.g. heteroatoms, enolates, organometallic reagents,...) and reactions have either been reported under transition metal catalysis ${ }^{10}$ or under transition metal-free (sometimes organocatalytic) conditions, ${ }^{11-15}$ thus highlighting their diverse applicability. In addition, it should also be noted that there are several approaches that rely on the use of simple cyanides like $\mathrm{Na}(\mathrm{K}) \mathrm{CN}$ or TMSCN

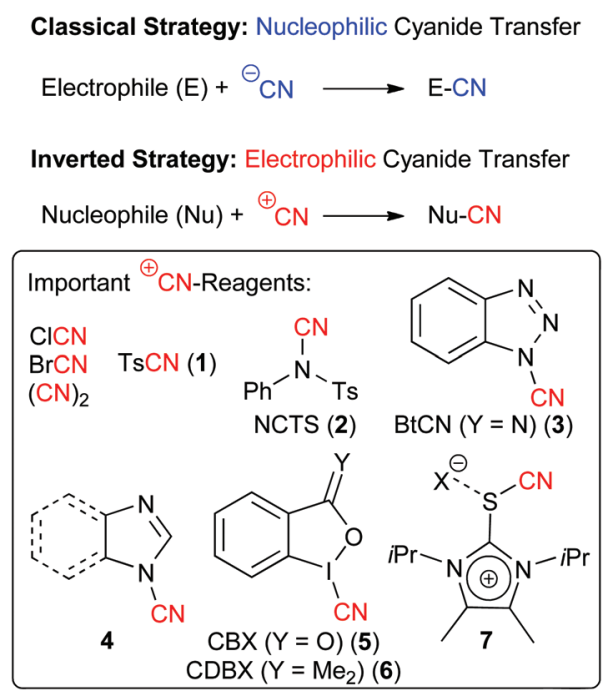

Scheme 1 Nucleophilic vs. electrophilic cyanide transfer strategies and depiction of some of the most important electrophilic $\mathrm{CN}^{+}$transfer reagents. TsCN ( $p$-toluenesulfonyl cyanide, 1 ), NCTS ( $N$-cyano- $N$ phenyl-p-toluenesulfonamide, 2), BtCN (1-cyanobenzotriazole, 3), ImCN (1-cyanoimidazole, 4a), BiCN (1-cyanobenzimidazole, 4b) CBX (1-cyano-1,2-benziodoxol-3-(1H)-one, 5), CDBX (1-cyano-3,3-dimethyl3-(1H)-1,2-benziodoxol, 6). under oxidative conditions, which then results in the in situ formation of electrophilic $\mathrm{CN}^{+}$-species. ${ }^{16}$

Altogether it is therefore without doubt that electrophilic cyanation strategies either under metal-mediated or metal-free conditions became tremendously versatile, and the last years have seen an increasing number of highly spectacular reports that brought these approaches to a new level with respect to application scope and also with respect to the development of stereoselective protocols. Based on this recent boost in the field, especially with respect to transition metal-free approaches, we hereby wish to highlight some of the most actual developments describing the use of the electrophilic CN-transfer reagents 1-7 under transition metal-free conditions.

\section{$N$-Cyano sulfonamides}

$N$-Cyano sulfonamides (i.e. TsCN 1 and NCTS 2) have been known for decades ${ }^{2}$ and belong to the most widely used electrophilic cyanide-transfer reagents. Especially NCTS became very often the reagent of choice in transition-metal catalysed cyanation reactions, which was impressively demonstrated by numerous groups recently. ${ }^{10}$ In addition, these $N$-cyanosulfonimides turned out to be very powerful in radical reactions. ${ }^{12}$ Besides, these compounds can also be used very generally for reactions with a variety of nucleophiles under transition metal-free conditions, which was demonstrated by Kahne and Collum who used tosylcyanide $\mathbf{1}$ for the cyanation of ketone enolates in 1981 already. ${ }^{4}$

In 2011, Beller and co-worker reported the direct cyanation of aryl and heteroaryl Grignard reagents which gave access to a broad diversity of benzonitrile derivatives $\mathbf{1 0}$ in high yields (Scheme 2A). ${ }^{11 a}$ To prove the potential of this robust method they also synthesized the more advanced derivatives 10a and 10b which serve as building blocks for the neo-nicotinioid insecticide Imidocloprid (11) and the PPARd agonist GW 0742 (12). ${ }^{11 a}$ At the same time, Wang et al. showed that NCTS can be used to facilitate the high yielding and site-selective direct cyanation of pyrroles and indoles $\mathbf{1 3}$ under Lewis acid-catalysis (Scheme 2B). ${ }^{11 b}$

Besides cyanation of aromatic substrates, $N$-Cyano sulfonamides were recently also successfully used for the $\alpha$-cyanation of carbonyl compounds. In 2013, Ibrahim et al. showed that tosylcyanide 1 can serve as the $\mathrm{CN}$-transfer reagent of choice to facilitate the high yielding $\alpha$-cyanation of 1,3-dicarbonyl compounds 15 under operationally simple basic conditions (Scheme 3A). ${ }^{11 c}$

Very recently, the group of Minakata and Kiyokawa succeeded in lifting the use of these simple CN-transfer reagents to a new level with respect to its application scope by developing an elegant direct cyanation of boron enolates 18 under mild conditions (Scheme $3 \mathrm{~B}$ ). ${ }^{11 f}$ This impressive protocol not only gives $\beta$-ketonitriles 19 in very high yields starting from simple ketone precursors 17 (which can be converted to $\mathbf{1 8}$ upon treatment with 20) but can also be applied to the use of easily accessible $\alpha, \beta$-unsaturated ketones 21 , which upon treatment with 9-BBN (22) give the enolates 18 that are then directly 
A) Beller et al. (2011):

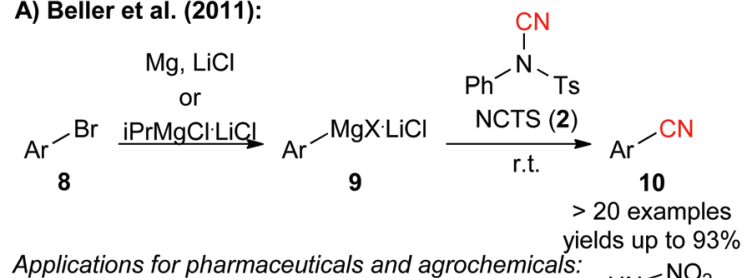

Applications for pharmaceuticals and agrochemicals: $\mathrm{HN}-\mathrm{NO}_{2}$<smiles>C=CC#N</smiles><smiles>NC1=NCCN1Oc1ccc(Cl)nc1</smiles><smiles>C=CC#N</smiles>

$10 \mathrm{~b}$<smiles>Cc1ccc(-c2nc(C)c(CSc3ccc(OCC(=O)O)c(C)c3)s2)cc1F</smiles>

GW 0742 (12)

B) Wang et al. (2011):<smiles>[R][Y14]1cccc2cc([R])n([R1])c12</smiles><smiles>[Y6][Y4]1cccc2c(C#N)c([R])n([R10])c12</smiles>

Scheme 2 NCTS (2) in the direct synthesis of aryl-carbonitriles.

A) Ibrahim et al. (2013):
$\mathrm{R}^{1} \stackrel{\text { H }}{\stackrel{\mathrm{O}}{\mathrm{O}^{2}}}+\mathrm{TsCN}(1) \stackrel{\mathrm{K}_{2} \mathrm{CO}_{3}}{\text { r.t. }}$

15

B) Kiyokawa, Minakata et al. (2016):<smiles>[R]CC([R7])C([R])=O</smiles><smiles>[R]CC([R])=C([R])O[R16]</smiles><smiles>[R]C=C([R1])C([R])=O</smiles>
18 (formed in situ)

22

Proof of concept for an asymmetric approach:

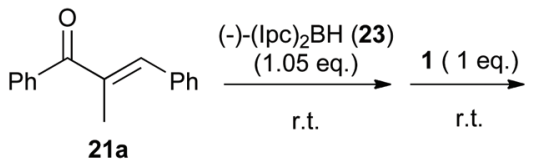<smiles>CC(C#N)(Cc1ccccc1)C(=O)c1ccccc1</smiles>

$19 \mathrm{a}$ $17 \%, 94 \%$ ee<smiles>BC1BC2CCCC1CCC2</smiles>

Scheme $3 \mathrm{~N}$-Cyano sulfonamides 1 and 2 for the $\alpha$-cyanation of enolates.
A) Kasthuri et al. (2015):

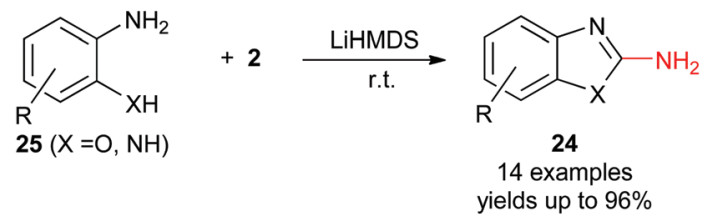

B) Moses, Sharma et al. (2016):

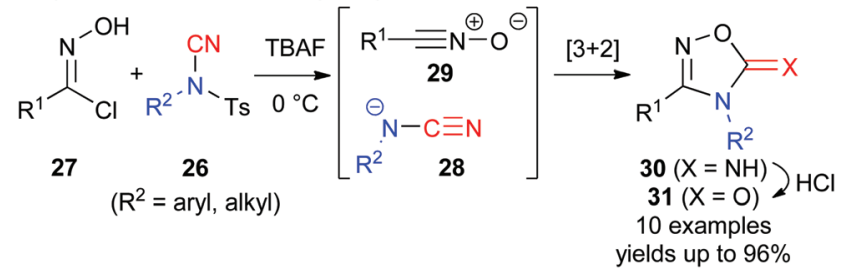

Scheme $4 \quad N$-Cyano sulfonamides for heterocycle-forming reactions.

trapped by either TsCN (1) or NCTS (2). The authors also succeeded in providing a first proof of concept for an asymmetric variant of this strategy by using diisopinocampheylborane 23 to generate a chiral boron enolate. However, it is fair to say that this protocol is so far limited by its low yield (noteworthy 2 did not give any product 19a hereby!) but it seems very likely that the authors will find a solution to address this limitation soon.

In addition to the use of NCTS and TsCN for carboncarbon bond forming reactions (catalysed or uncatalysed) these reagents can also be used for the synthesis of highly functionalized heterocycles such as 2-amino-benzoxazoles or -benzimidazoles $24 .^{11 d}$ These targets are traditionally often accessed by reaction of aminophenols or aminoanilines 25 with cyanogen bromide under forcing conditions. ${ }^{17}$ In search for a safer and more practical approach, Kasthuri et al. found that reagent 2 can be successfully used to access a broad variety of these important target molecules and much milder and less toxic conditions (Scheme 4A). ${ }^{11 d}$

Very recently, the groups of Moses and Sharma found that a broad variety of NCTS derivatives 26 can also be employed very elegantly for so far unprecedented formal 1,3-dipolar [3+2]cyclization reactions with nitrile oxides 27 in the presence of tetrabutyl ammonium fluoride (TBAF). ${ }^{11 e}$ This new strategy is based on the cyclization of the in situ generated cyanamide anion 28 with nitrile oxide 29 to obtain the 1,2,4-oxadiazol-5imines 30 in high yields. Such compounds or the analogous 1,2,4-oxadiazol-5-ones 31 (easily obtained by hydrolysis) are key-structural motives that are frequently found in pharmaceutically interesting targets and thus this recent strategy provides a very elegant alternative synthesis approach to access these valuable compounds in a straightforward manner. ${ }^{11 e}$

\section{Cyanobenzotriazole and cyano(benz) imidazole}

1-Cyanobenzotriazole (3) has been frequently used as an electrophilic cyanation reagent since the middle of the 1990s. ${ }^{5}$ 
In general this reagent can as well be used for reactions with either heteroatom or with C-nucleophiles. For example, in 2007 the Katritzky group showed that 3 can be used for reactions with different in situ-formed Li-carbanions in good yields (Scheme 5A). ${ }^{13 a}$ In 2012, the group of A. B. Smith III then relied on a diastereoselective early stage $\alpha$-cyanation of the bicyclic lactone 34 in their impressive total synthesis of the monoterpenoid indole alkaloid scholarisine A (36) (Scheme 5B). ${ }^{13 b}$

Very recently Audisio and co-workers also showed that $\left[{ }^{14} \mathrm{C}\right]$-radiolabelled BtCN can be formed in situ from $\left[{ }^{14} \mathrm{C}\right]$ labelled $\mathrm{KCN}$ and $\mathrm{N}$-chlorobenzotriazole. This $\left[{ }^{14} \mathrm{C}\right]$-radiolabelled BtCN was then successfully reacted with aminophenols 25 to obtain labelled derivatives of $\mathbf{2 4}$ (compare with Scheme 4) that served as building blocks towards $\left[{ }^{14} \mathrm{C}\right]$-radiolabelled herbicide agents. ${ }^{13 c}$

Besides the recently very frequently used BtCN (3) also 1-cyano(benz)imidazoles 4 were found to be highly interesting electrophilic CN-transfer agents. In 2000, Wu et al. have shown that 1-cyanoimidazole (4a) can be reacted with a variety of heteroatom or organometallic nucleophiles (Scheme 6A), ${ }^{9 d}$ and in 2010, Beller's group reported the straightforward and high yielding electrophilic cyanation of a variety of aryl Grignard reagents 9 with $N$-cyanobenzimidazole (4b)

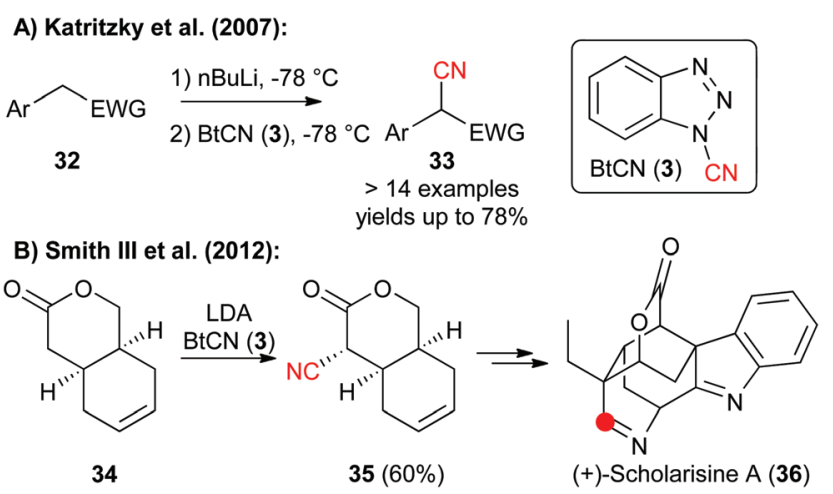

Scheme 5 BtCN-mediated $\alpha$-cyanation reactions of enolates.

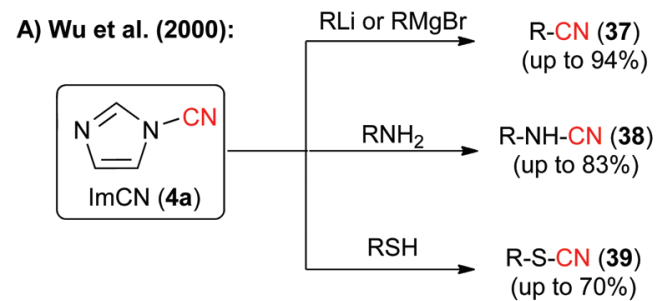

B) Beller et al. (2010):
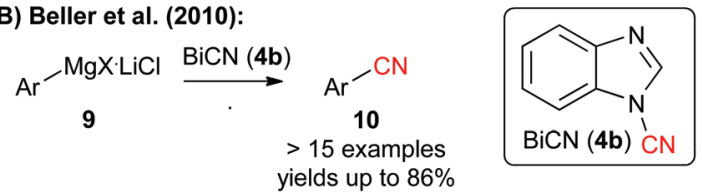

Scheme 6 Cyano(benz)imidazole mediated reactions.
(Scheme 6B, please compare also with the alternative approach by the same group shown in Scheme $2 \mathrm{~A}) .{ }^{9 e}$

\section{Hypervalent iodine-based reagents}

Hypervalent iodine-based reagents have become increasingly important electrophilic reagents allowing for the Umpolung of the inherent reactivity of a broad variety of different functionalities. ${ }^{18}$ In addition, the oxidation potential of hypervalent iodine reagents also allows for their use to generate highly reactive species in situ. The versatility of such a strategy for cyanation reactions was impressively demonstrated in the past using simple cyanides like TMSCN as the CN-source. ${ }^{16 c, e}$ Interestingly tough, cyanide-containing iodine reagents like compounds 5 and $\mathbf{6}$ have been known for more than 20 years. ${ }^{6}$ Surprisingly, their potential as electrophilic CN-transfer has been more or less neglected until two years ago. ${ }^{14}$ Worth to note, 2015 then saw an increasing interest in these compounds and within just a few months three independent reports describing the use of the benziodoxole $\mathbf{5}$ for the $\alpha$-cyanation of $\beta$-ketoesters and amides $\mathbf{4 0}$ have been published (Scheme 7A). ${ }^{14 a, d, e}$ Chen et al. first showed that a racemic version of this reaction proceeds within very short time (10 $\mathrm{min}$ ) under ambient conditions for a variety of different nucleophiles. ${ }^{14 a}$ They also demonstrated that for this reaction the benziodoxole 5 clearly outperforms other $\mathrm{CN}$-reagents like 3, 6 or BrCN. Shortly after, our group showed that this transformation can be rendered enantioselective by using cinchona alkaloids as chiral organocatalysts. ${ }^{14 d}$ However, the selectivities were only modest (less than $52 \%$ ee). Very impressively however, the group of Zheng soon afterwards found that the

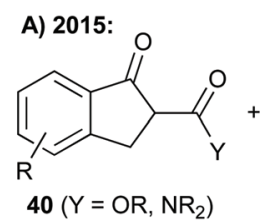<smiles>N#CI1OC(=O)c2ccccc21</smiles>

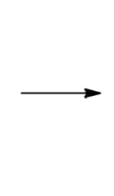<smiles>[R]c1cccc2c1CC(C#N)(C#N)C2=O</smiles>

Chen et al.: base free racemic approach (10 min, yields up to $95 \%$ ) Waser M. et al.: Cinchona alkaloid catalysis (up to $52 \%$ ee) Zheng et al.: Chiral phase-transfer catalysis (up to $93 \%$ ee)

B) Waser J. et al. (2015):
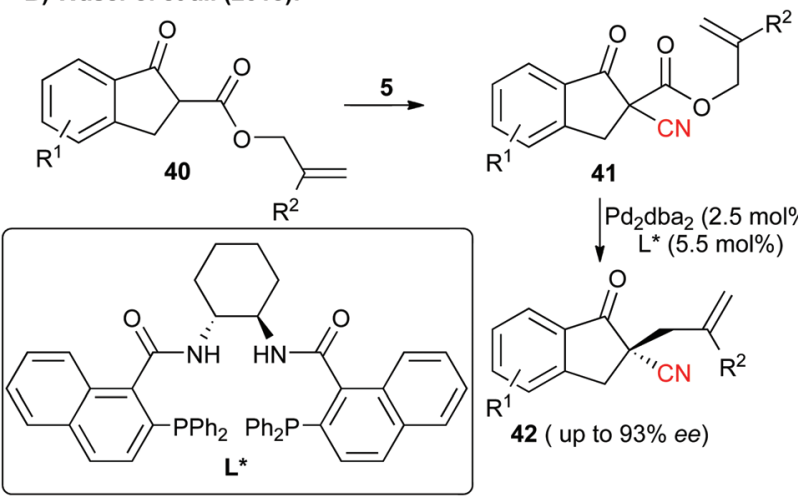

$\mathrm{Pd}_{2} \mathrm{dba}_{2}(2.5 \mathrm{~mol} \%)$ $L^{*}(5.5 \mathrm{~mol} \%)$

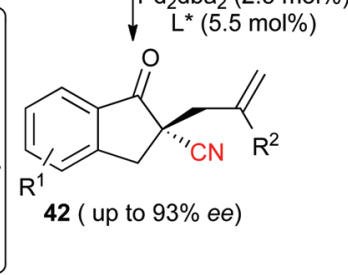

Scheme 7 CBX (5)-mediated $\alpha$-cyanation reactions of $\beta$-ketoesters. 


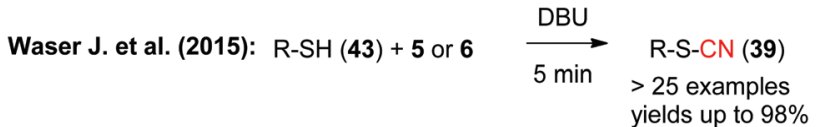

Scheme 8 Hypervalent iodine reagents 4 and 5 for the synthesis of thiocyanates.

combination of a chiral phase-transfer catalyst (based on cinchona alkaloids) with an organic base (DMAP) allows them to obtain these valuable target with good to excellent selectivities. ${ }^{14 e}$

Also in 2015, Jerome Waser's group introduced an alternative strategy to access similar chiral cyano indanone derivatives 42 by first carrying out a racemic $\alpha$-cyanation of allyl ketoesters and then controlling the decarboxylative allylation with asymmetric palladium catalysis to obtain the valuable chiral targets 42 with satisfying selectivities. ${ }^{14 c}$

The same group also succeeded in using the hypervalent iodine reagents 5 and $\mathbf{6}$ to facilitate the cyanation of thiols $\mathbf{4 3}$ to obtain the corresponding thiocyanates 39 with excellent yields (Scheme 8). Noteworthy, in this study they have not only shown that this method works very robust on broad substrate scope, but they also provide rather detailed mechanistic studies and also proved that the reaction can be expanded towards the analogous selenol derivatives. ${ }^{14 b}$

It is also worth to note that very recently Studer's group reported the use of aryl(cyano)iodonium triflates for the synaddition of a cyanide and a triflate group to alkynes. ${ }^{19}$ Although not perfectly within the intended scope of this article as the presence of $\mathrm{Fe}(\mathrm{OAc})_{2}$ as a promoter was found to essential for this transformation, it clearly represents another highly spectacular example for the potential of these unique CN-transfer reagents. ${ }^{20}$

\section{Imidazolium thiocyanates}

As mentioned already all the electrophilic CN-transfer reagents discussed so far have been known for quite a while, but it was only more recently that they found really widespread synthetic applications, as highlighted in the preceding subchapters. This is clearly different with the last class discussed herein, which is the new family of imidazolium thiocyanates $\mathbf{6}$, that was introduced by Alcarazo's group in $2015 .{ }^{15}$ These unique reagents (being isolobal to iodine(III) compounds) were accessed in multigram quantities and showed really spectacular cyanide transfer properties (as a short side note: the authors also demonstrated the high alkyne-transfer potential of analogous compounds in their seminal study ${ }^{15}$ ). As can be seen in Scheme 9, transfer reagent 7 could be successfully employed under either basic or Lewis acidic conditions (depending on the substrate) to facilitate enolate cyanations (even of simple ketones), to cyanate electron richer (hetero)aromatic compounds or to react with sulfides or amines. Thus it can be said without doubt that these reagents have the poten-

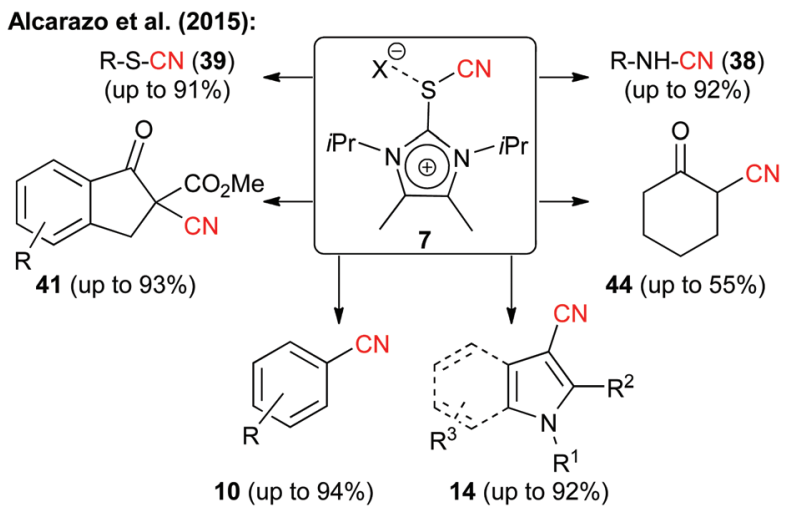

Scheme 9 Imidazolium thiocyanate 7 as an electrophilic $\mathrm{CN}$-transfer reagent.

tial to really become a privileged scaffold for new electrophilic transfer reagents, and it should only be a matter of time before we will see more applications making use of this methodology and hopefully even in an asymmetric fashion.

\section{Conclusions}

The last years have seen very remarkable developments by making use of the unique reactivity of electrophilic cyanidetransfer reagents. New methods have appeared and the synthesis strategies that were introduced so far really provide exciting new tools for synthetic organic chemists, which was also already proven in some case studies towards the synthesis of biologically active structurally demanding target molecules. More recently, a new class of very promising transfer reagents, imidazolium thiocyanates 7 , were introduced which will hopefully open further directions in the field. The last years have also seen the first reports of enantioselective electrophilic cyanation protocols and it is without question that also this, so far still more challenging task, will mature pretty soon, keeping in mind the enormous progress the whole field has made in just a few years now and thus we are confident that these cyanation strategies will soon find their way into the standard synthesis repertoire of organic chemists.

\section{Notes and references}

1 For detailed overviews see: (a) Science of Synthesis, ed. S.-I. Murahashi, Thieme, 2004, vol. 19; (b) P. Merino, in Comprehensive Organic Synthesis II, ed P. Knochel and G. A. Molander, Elsevier, 2014, pp. 697-750; (c) J. Kim, H. J. Kim and S. Chang, Angew. Chem., Int. Ed., 2012, 51, 11948.

2 For the initial report describing the synthesis of $\mathrm{N}$-cyanosulfonamides see: F. Kurzer, J. Chem. Soc., 1949, 1034.

3 For a seminal report about enolate cyanation with cyanogen chloride see: M. E. Kuehne and J. A. Nelson, J. Org. Chem., 1970, 35, 161. 
4 For an early report describing the use of tosylcyanide for enolate cyanation see: D. Kahne and D. B. Collum, Tetrahedron Lett., 1981, 22, 5011.

5 Seminal reports about the use of 1-cyanobenzotriazole as an electrophilic cyanation reagent: (a) S. Thambidura, K. Jeyasubramanian and S. K. Ramalingam, Polyhedron, 1996, 15, 4011; (b) T. V. Hughes, S. D. Hammond and M. P. Cava, J. Org. Chem., 1998, 63, 401.

6 First reports of cyclic cyano-benziodoxoles: (a) V. V. Zhdankin, C. J. Kuehl, A. P. Krasutsky, J. T. Bolz, B. Mismash, J. K. Woodward and A. J. Simonsen, Tetrahedron Lett., 1995, 36, 7975; (b) S. Akai, T. Okuno, M. Egi, T. Takada, H. Tohma and Y. Kita, Heterocycles, 1996, 42, 47.

7 V. Kumar, Synlett, 2005, 1638.

8 S. Mo, Synlett, 2014, 1337.

9 A variety of other derivatives have been reported in the past too and for some chosen examples please see: (a) J. Bergman and B. Pelcman, Tetrahedron Lett., 1986, 27, 1939; (b) P. P. Purygin, S. V. Pan'kov, N. A. Belyakov and O. N. Labazova, Russ. J. Gen. Chem., 2002, 72, 1286; (c) N. Sato and Q. Yue, Tetrahedron, 2003, 59, 5831; (d) Y.-Q. Wu, D. C. Limburg, D. E. Wilkinson and G. S. Hamilton, Org. Lett., 2000, 2, 795; (e) P. Anbarasan, H. Neumann and M. Beller, Chem. - Eur. J., 2010, 16, 4725.

10 For some selected highly impressive examples using NCTS in transition metal-catalysed reactions please see: (a) P. Anbarasan, H. Neumann and M. Beller, Angew. Chem., 2011, 123, 539; (b) T.-J. Gong, B. Xiao, W.-M. Cheng, W. Su, J. Xu, Z.-J. Liu, L. Liu and Y. Fu, J. Am. Chem. Soc., 2013, 135, 10630; (c) M. Chaitanya, D. Yadagiri and P. Anbarasan, Org. Lett., 2013, 15, 4960; (d) Y. Yang and S. L. Buchwald, Angew. Chem., 2014, 126, 8821; (e) D.-G. Yu, T. Gensch, F. de Azambuja, S. Vasquez-Cespedes and F. Glorius, J. Am. Chem. Soc., 2014, 136, 17722; $(f)$ J. Li and L. Ackermann, Angew. Chem., 2015, 127, 3706.

$11 \mathrm{~N}$-Cyanosulfonamides: (a) P. Anbarasan, H. Neumann and M. Beller, Chem. - Eur. J., 2011, 17, 4217; (b) Y. Yang, Y. Zhang and J. Wang, Org. Lett., 2011, 13, 5608; (c) R. Akula, Y. Xiong and H. Ibrahim, RSC Adv., 2013, 3, 10731; (d) M. Kasthuri, H. S. Babu, K. S. Kumar, C. Sudhakar and P. V. N. Kumar, Synlett, 2015, 897; (e) S. V. Bhat, D. Robinson, J. E. Moses and P. Sharma, Org.
Lett., 2016, 18, 1100; $(f)$ K. Kiyokawa, T. Nagata and S. Minakata, Angew. Chem., Int. Ed., 2016, 55, 10458.

12 Examples about the use of $N$-cyanosulfonimides in radical reactions: (a) S. Kim and C. J. Lim, Angew. Chem., Int. Ed., 2002, 41, 3265; (b) A.-P. Schaffner, V. Darmency and P. Renaud, Angew. Chem., Int. Ed., 2006, 45, 5847.

13 BtCN: (a) A. R. Katritzky, R. Akue-Gedu and A. V. Vakulenko, ARKIVOC, 2007, 5; (b) G. L. Adams, P. J. Carroll and A. B. Smith III, J. Am. Chem. Soc., 2012, 134, 4037; (c) O. Loreau, N. Camus, F. Taran and D. Audisio, Synlett, 2016, 1798.

14 Hypervalent iodine reagents: (a) Y.-F. Wang, J. Qiu, D. Kong, Y. Gao, F. Lu, P. G. Karmaker and F.-X. Chen, Org. Biomol. Chem., 2015, 13, 365; (b) R. Frei, T. Courant, M. D. Wodrich and J. Waser, Chem. - Eur. J., 2015, 21, 2662; (c) M. V. Vita, P. Caramenti and J. Waser, Org. Lett., 2015, 17, 5832; (d) R. Chowdhury, J. Schörgenhumer, J. Novacek and M. Waser, Tetrahedron Lett., 2015, 56, 1911; (e) M. Chen, Z.-T. Huang and Q. Y. Zheng, Org. Biomol. Chem., 2015, 13, 8812.

15 G. Talavera, J. Pena and M. Alcarazo, J. Am. Chem. Soc., 2015, 137, 8704.

16 For seminal and also more recent illustrative examples see: (a) K. Koyama, T. Susuki and S. Tsutsumi, Tetrahedron Lett., 1965, 11, 627; (b) L. Eberson and F. Radner, Acta Chem. Scand., 1992, 46, 312; (c) T. Dohi, K. Morimoto, N. Takenaga, A. Goto, A. Maruyama, Y. Kiyono, H. Tohma and Y. Kita, J. Org. Chem., 2007, 72, 109; (d) C. Zhu, J.-B. Xia and C. Chen, Org. Lett., 2014, 16, 247; (e) H. Shen, J. Li, Q. Liu, J. Pan, R. Huang and Y. Xiong, J. Org. Chem., 2015, 80, 7212.

17 For an example see: J. P. Powers, S. Li, J. C. Jaen, J. Liu, N. P. C. Walker, Z. Wang and H. Wesche, Bioorg. Med. Chem. Lett., 2006, 16, 2842.

18 For two recent reviews see: (a) A. Yoshimura and V. V. Zhdankin, Chem. Rev., 2016, 116, 3328; (b) Y. Li, D. P. Hari, M. V. Vita and J. Waser, Angew. Chem., Int. Ed., 2016, 128, 4512.

19 X. Wang and A. Studer, J. Am. Chem. Soc., 2016, 138, 2977.

20 It should however be mentioned that it was recently shown that reagent $\mathbf{5}$ cannot be used to cyanate Li-acetylides: J. Schörgenhumer and M. Waser, Tetrahedron Lett., 2016, $57,1678$. 